\title{
Suicide by different methods
}

\author{
R. D. T. FARMER \\ M.R.C.S., L.R.C.P. \\ Department of Community Medicine, Westminster Medical School, London
}

\begin{abstract}
Summary
The annual numbers of suicide deaths for the past $\mathbf{1 0 0}$ years by different methods in England and Wales are presented. It is shown that the numbers of deaths by 2 methods, domestic gas poisoning and poisoning by solid or liquid substances, vary independently of all other methods. It is concluded that inferences as to cause drawn from aggregated data should be viewed with great caution.
\end{abstract}

\section{Introduction}

Most work on the association between suicide mortality and other temporal, social and political variables has used aggregated suicide mortality data. This assumes that any variations in suicide mortality by specific methods do not affect the total numbers of suicide deaths. An increase in suicide mortality by a particular method has been seen to be of interest only in that it affects the proportion of suicides by that method within the total suicide mortality. Durkheim (1897) dismissed the analyses of variations in suicide rates as 'adding nothing to the results given in our previous studies'.

More recently suicide by one particular method, coal gas poisoning, has been subjected to some detailed scrutiny (Hassall and Trethowan, 1972; Kreitman, 1976). It has been shown that at least during the post-war period, mortality from suicide by coal gas poisoning seems to have been related to the supply of toxic domestic gas. Adelstein and Mardon (1975) showed that the recent decline in suicide mortality in England and Wales is accounted for by the decline in domestic gas deaths.

If recorded mortality from suicide by different methods varies independently of each other then inferences drawn from aggregated data may be misleading. Some observations are now reported on the variations in recorded mortality from suicide in England and Wales by different methods over the past 100 years.

\section{Method}

The annual numbers of deaths by suicide for males and females separately by 6 specific methods and by all methods together were abstracted from annual reports of the Registrar General for England and Wales (Annual Reports). The methods chosen for study and their current ICD* code were as follows: suicide by poisoning by solid or liquid substances (E950), by poisoning by gases in domestic use (E951), by hanging, stangulation and suffocation (E953), by submersion (E954), by firearms, and explosives (E955) and by cutting and piercing instruments (E956). The methods were selected for 2 reasons. Firstly, because jointly they constituted the bulk of all suicides $(90 \%)$ and secondly, because they were identifiable as discrete categories throughout the period 1876-1975, although there were many changes in the coding system used throughout the period.

\section{Results}

Figure 1 shows the annual numbers of deaths from suicide by all methods. There are 4 remarkable features: (i) Since the early 1960s there has been a substantial and sustained fall in mortality in both sexes; (ii) the number of recorded deaths fell during both World Wars. However, the decrease amongst females was proportionately less than amongst males; (iii) the male : female ratio has generally decreased over the years studied; (iv) there was a peak in male deaths in 1931, during economic depression, but no clear peak in female deaths.

There was no marked decrease in incidence during either of the 2 wars, in suicide deaths by firearms (Fig. 2) or by cutting and piercing instruments (Fig. 3). The annual number of male deaths by firearms has remained unchanged for many years. However, this method is so rare amongst women that no conclusions can be drawn from them. The decline in mortality from suicidal cutting and piercing began in the early 1930 s and the trend has continued until the 1960 s.

Male suicidal drownings (Fig. 4) decreased substantially during the first war, but female drownings altered little. Since 1931 there has been a sustained

\footnotetext{
* International Classification of Disease.
} 


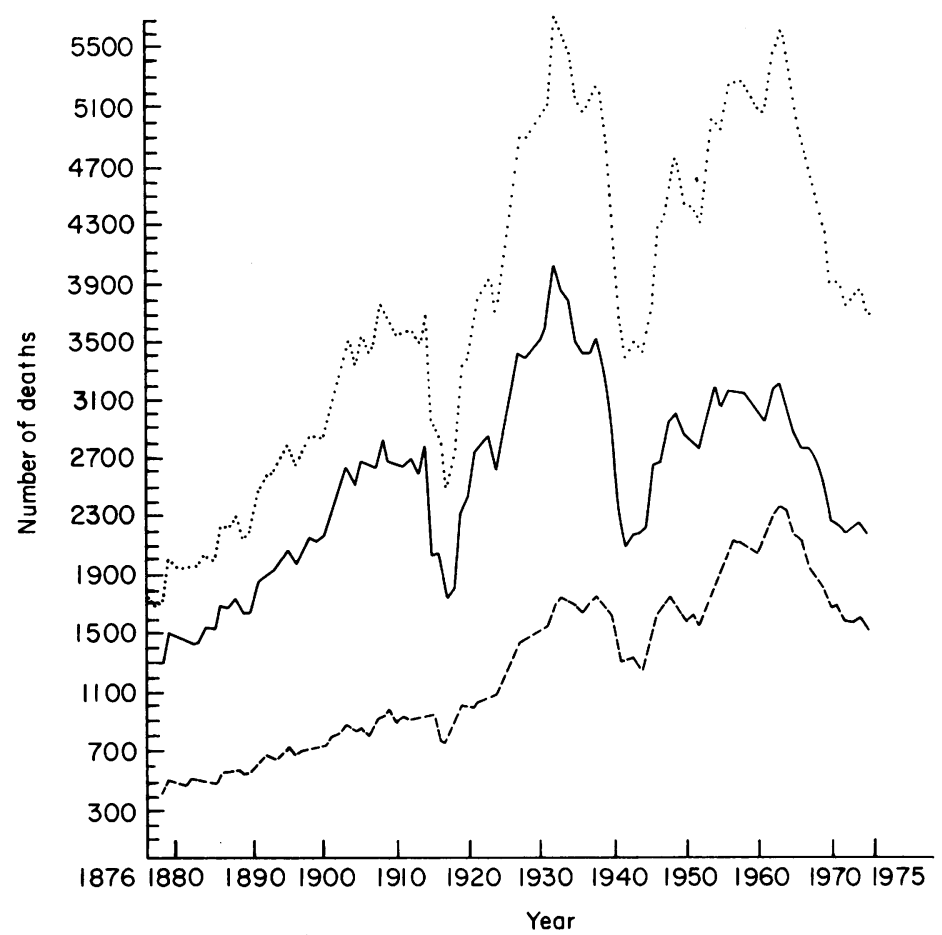

Fig. 1. Total number of suicides $1876-1975$. - Male, - - female, $\cdots$ total.

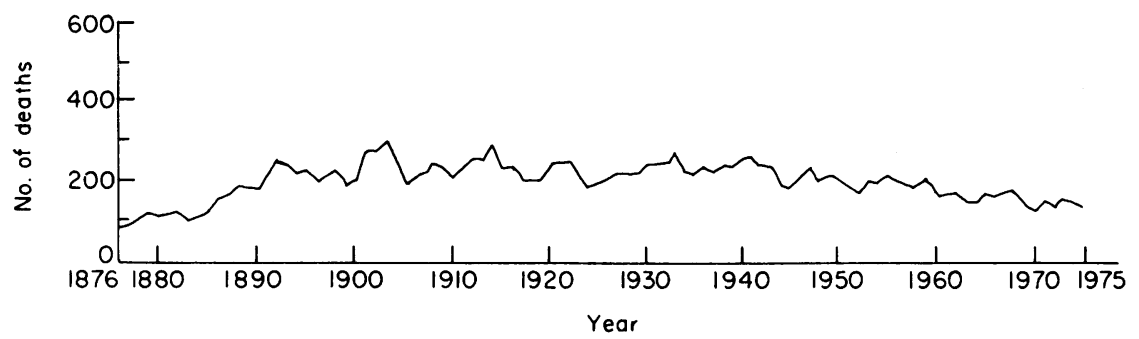

FIG. 2. Number of suicides by firearms $1876-1975$. _ Male.

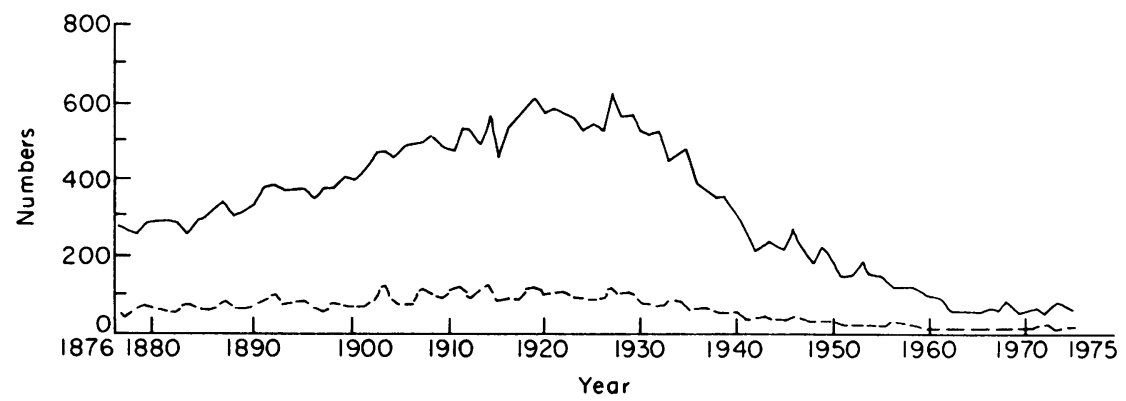

FIG. 3. Number of suicides by cutting and piercing 1876-1975. _— Male, $\ldots$ - female. 


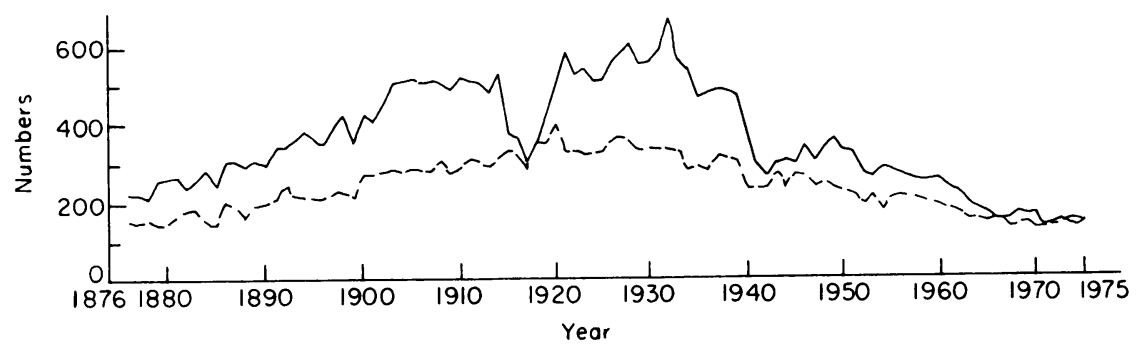

FIG. 4. Number of suicides by drowning 1876-1975. _— Male, - - female.

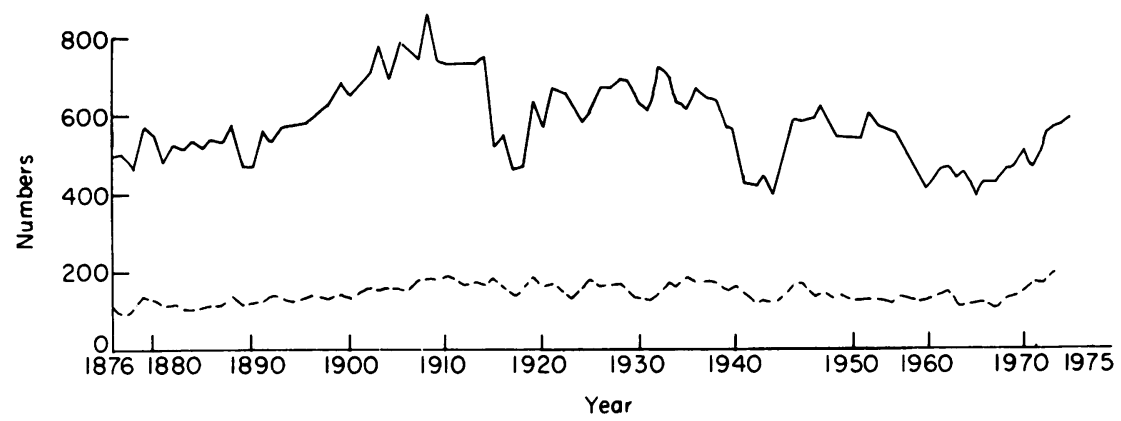

Fig. 5. Number of suicides by hanging 1876-1975. _ Male, - - female.

annual decrease in the numbers until the 1960s. The expected decrease during World War II is almost lost in this general decline. Since World War II the male : female ratio has decreased.

There were sharp decreases in male suicidal hangings in both wars (Fig. 5); this did not occur amongst females. There was no increase in the number of hangings in 1931. The male : female ratio has changed relatively little throughout the period, excluding the war years.

Figure 6 shows the numbers of suicidal deaths by coal gas poisoning. This method was not used until the 1920s and so no decrease during World War I is apparent. In neither sex is there a peak in 1931. The fall in numbers of deaths during the second war was more marked amongst males than it was amongst females. There has been a sustained fall since the early 1960 s. The male : female ratio is smaller than that of any of the other methods presented so far.

The trends for suicidal poisonings (Fig. 7) are unique. The number of deaths decreased during both wars. There was no increase in 1931. After World War II there was an increase in deaths and this reached a plateau in 1962. During World War II the sex ratio reversed, so that currently there are more female than male deaths. This is the only method that shows such a sex ratio.

Numbers of suicides for both sexes together by all the foregoing methods except firearms are plotted together in Fig. 8. Until World War II, cutting, drowning, hanging and poisoning tended to vary together. Throughout the period, poisoning by domestic gas varied independently of all other methods, apart from a decrease during World War II. It should be noted that the decline in coal gas poisoning continued after suicide by poisoning had reached a plateau.

\section{Discussion}

The observed trends in overall suicide mortality are the sum of suicides by different methods. If particular methods are important only inasmuch as they alter the proportion available to the various methods within an aggregate, then it is to be expected that there will be a formal relationship, e.g. some increase as others decrease, between deaths by different methods. The fact that the variations in domestic gas suicides for the whole period and suicidal poisonings for the past 25 years behave independently is not consistent with that hypothesis.

There are several possible explanations for these findings. There may be variations in the ascertainment rate of suicide by different methods. The recording of suicide first involves detection of a death as not being due to natural causes; once it is appreciated that external causes are involved, a verdict of suicide has to be reached by a coroner.

Many methods of suicide are obviously unnatural 


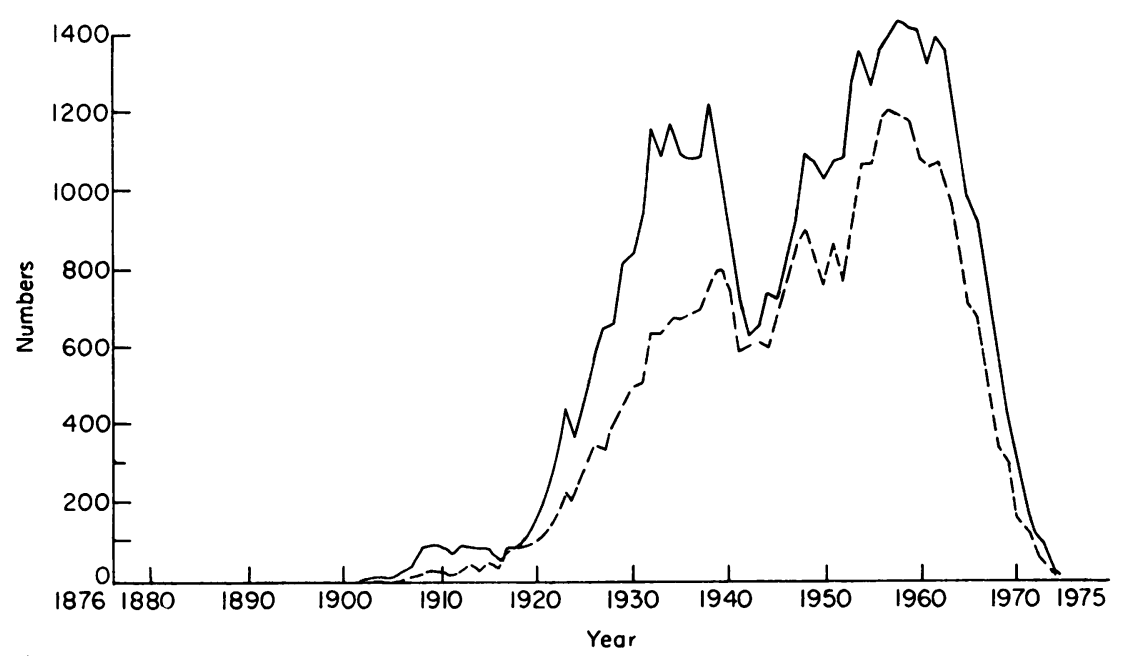

FIG. 6. Number of suicides by coal gas poisoning 1876-1975. _ Male, - . - female.

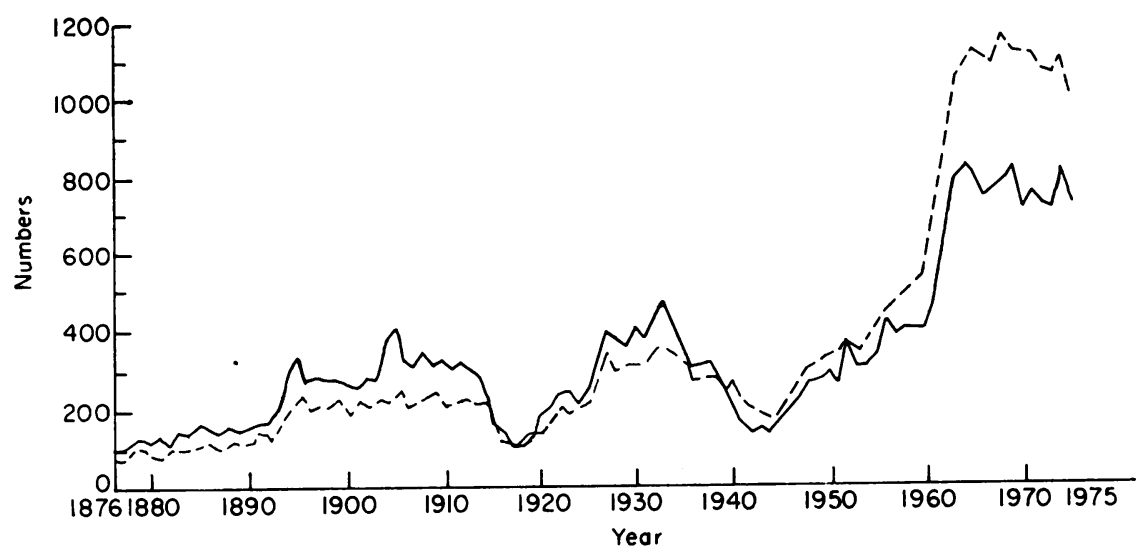

Fig. 7. Number of suicides by poisoning 1876-1975. — Male, - - - female.

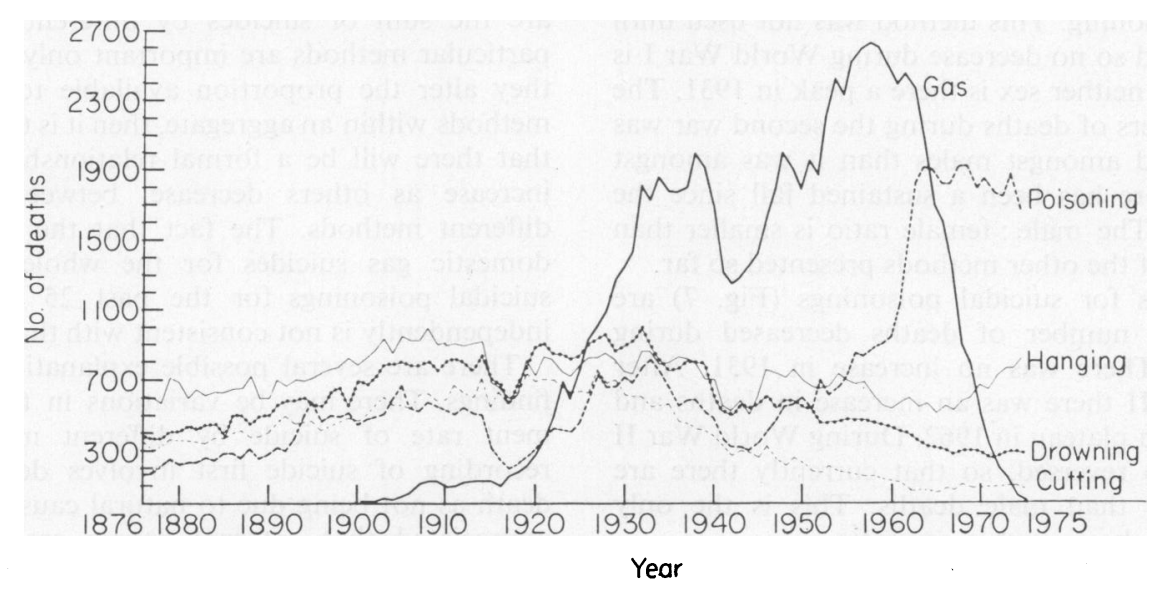

FIG. 8. Number of suicides by various methods 1876-1975. 
deaths - most violent methods fall into this category. With the exception of the war years these methods (hanging, drowning, firearms and cutting and piercing) show the least dramatic variations, although some do show long-term secular trends. Poisoning by gas or by solid or liquid substances are less likely to be recognized as being due to outside interference. Patel (1973) described the position: 'The use of these drugs requires no witnesses, they do not leave behind visible marks and present a picture similar to that of a natural death . . . Therefore, General Practitioners when requested to call to attend dying or dead patients, have nothing to suspect and, if the patient is dead, they issue certificates without hesitation'.

Possible variations in assignation can best be explained by examining the proportionate distribution of each method between the 3 categories of suicide, undetermined (open verdicts) and accidents. It has previously been reported that the proportion of deaths assigned to each of the 3 categories has varied in recent times (Kreitman, 1976; Patel, 1973). Thus the variations within method may be artefactual owing to differences in the proportion of true suicides that are recognized as such.

An alternative explanation is that the factors influencing suicide mortality by one method may differ from those influencing mortality by another method, in part at least. This hypothesis is certainly an attractive one in the case of suicidal domestic gas poisonings, since their numbers correlate with gas supply. Furthermore the change in the numbers of poisonings by solid and liquid substance is consistent with the increase in the supply of drugs since the second war.

Whatever the reason for the differences in trends between methods, the differences are such that the use of aggregated suicide data to draw inferences concerning cause should be avoided.

\section{References}

Aldestein, A. \& Mardon, C. (1975) Suicides 1961-1974. Population Trends (OPCS) 2, 13. H.M. Stationery Office, London.

Annual Reports (1876-1975) Office of Population Censuses and Surveys. The Registrar General's Statistical Review of England \& Wales. H.M. Stationery Office, London.

DurKheIM, E. (1897) Suicide (Translated by J. A. Spaulding \& G. Simpson). Routledge \& Kegan Paul, 1957.

Hassall, C. \& Trethowan, W.H. (1972). Suicide in Birmingham. British Medical Journal, 1, 717.

Kreitman, N. (1976) The coal gas story: United Kingdom suicide rates, 1960-71. British Journal of Preventative and Social Medicine, 30, 86.

Patel, N.S. (1973). Pathology of suicide. Medicine, Science and Law, 13, 2. 